\title{
Prevalence and antifungal susceptibility of gastrointestinal candidiasis among diabetic patients: A cross-sectional study
}

\begin{tabular}{|c|c|}
\hline \multicolumn{2}{|c|}{$\begin{array}{l}\text { Authors: } \\
\text { Anthony P. Oyom }{ }^{1} \\
\text { Emmanuel Okello } \\
\text { Victoria Acam }{ }^{1} \\
\text { Christine Aramo } \\
\text { Bashir Mwambi } \\
\text { John C. Okiria } \\
\text { Caesar Oyet }{ }^{1}\end{array}$} \\
\hline $\begin{array}{l}\text { Affiliations: } \\
{ }^{1} \text { Department } \\
\text { Laboratory Sc } \\
\text { of Allied Heal } \\
\text { International } \\
\text { (formerly Inte } \\
\text { Health Scienc } \\
\text { Kampala, Uga }\end{array}$ & $\begin{array}{l}\text { f Medical } \\
\text { ences, Faculty } \\
\text { h, Clarke } \\
\text { Iniversity } \\
\text { national } \\
\text { s University), } \\
\text { da }\end{array}$ \\
\hline $\begin{array}{l}{ }^{2} \text { Department } \\
\text { Medicine and } \\
\text { Health, Facult } \\
\text { Health, Clarke } \\
\text { University (fo } \\
\text { International } \\
\text { University), K }\end{array}$ & $\begin{array}{l}\text { f Clinical } \\
\text { Community } \\
\text { of Allied } \\
\text { International } \\
\text { merly } \\
\text { lealth Sciences } \\
\text { mpala, Uganda }\end{array}$ \\
\hline $\begin{array}{l}\text { Correspondin } \\
\text { Caesar Oyet, } \\
\text { coyet@ihsu.a }\end{array}$ & author: \\
\hline $\begin{array}{l}\text { Dates: } \\
\text { Received: } 13 \\
\text { Accepted: } 12 \\
\text { Published: } 10\end{array}$ & $\begin{array}{l}\text { eb. } 2019 \\
\text { ung. } 2020 \\
\text { ec. } 2020\end{array}$ \\
\hline $\begin{array}{l}\text { How to cite th } \\
\text { Oyom AP, Oke } \\
\text { et al. Prevalen } \\
\text { antifungal sus } \\
\text { gastrointestin } \\
\text { among diabet } \\
\text { cross-sectiona } \\
\text { Med. 2020;9( } \\
\text { doi.org/10.41 }\end{array}$ & $\begin{array}{l}\text { is article: } \\
\text { lo E, Acam V, } \\
\text { e and } \\
\text { eptibility of } \\
\text { I candidiasis } \\
\text { e patients: A } \\
\text { study. Afr J Lab } \\
\text { ), a997. https:// } \\
\text { 2/ajlm.v9i1.997 }\end{array}$ \\
\hline $\begin{array}{l}\text { Copyright: } \\
\text { (C) 2020. The } \\
\text { Licensee: AOS } \\
\text { is licensed un } \\
\text { Creative Com } \\
\text { Attribution Lic }\end{array}$ & $\begin{array}{l}\text { uthors. } \\
\text { S. This work } \\
\text { er the } \\
\text { nons } \\
\text { ense. }\end{array}$ \\
\hline Read online: & \\
\hline 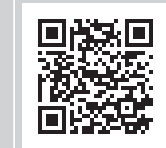 & $\begin{array}{l}\text { Scan this QR } \\
\text { code with your } \\
\text { smart phone or } \\
\text { mobile device } \\
\text { to read online. }\end{array}$ \\
\hline
\end{tabular}

Background: Gastrointestinal candidiasis is the most predominant opportunistic human mycosis, especially in diabetic patients. There is a global increase in antifungal resistance coupled with a rarity of information on antifungal susceptibility profiles in Uganda.

Objective: This study aimed to determine the occurrence and antifungal susceptibility of gastrointestinal candidiasis in diabetic patients.

Methods: Stool and fasting blood specimens were obtained from randomly sampled consenting patients with diabetes mellitus at St. Francis Hospital Nsambya in Kampala, Uganda to determine Candida infection, fasting blood glucose and glycated haemoglobin levels. Susceptibility testing was performed on Muller Hilton agar supplemented with $2 \%$ glucose and $0.2 \mu \mathrm{g}$ of methylene blue, using the E-test diffusion method.

Results: Among the 241 patients included in the analyses, the overall prevalence of gastrointestinal candidiasis was $15.4 \%(n=37)$. Candida albicans $(62.16 \%, n=23)$ was the predominant species, followed by Candida glabrata $(18.92 \%, n=7)$, Candida tropicalis $(8.11 \%$, $n=3)$, Candida krusei $(5.41 \%, n=2)$ and Candida dublinensis $(5.41 \%, n=2)$. Resistance was observed with miconazole $(48.65 \%)$, clotrimazole $(18.92 \%)$ and fluconazole $(8.11 \%)$. No resistance to itraconazole and nystatin was observed. Gastrointestinal candidiasis was associated with poor glucose control $(p \leq 0.001)$, prior use of antibiotics $(p \leq 0.001)$, antifungals $(p \leq 0.001)$ and corticosteroids $(p \leq 0.001)$ and was more common among female patients $(p=0.01)$.

Conclusion: Occurrence of gastrointestinal candidiasis was relatively low among our participants, and infection was associated with poor glucose control, female sex and use of antifungals, antibiotics and corticosteroids.

Keywords: candidiasis; diabetes; gastrointestinal; antifungal; susceptibility.

\section{Introduction}

Candida species reside in the human gastrointestinal tract as part of the body's microbiota. Due to changes in host environment (such as immunosuppression, metabolic imbalances and dysbiosis), they can proliferate as opportunistic pathogens. ${ }^{1,2}$ They are the predominant cause of opportunistic human mycoses, and are capable of causing superficial as well as invasive mycoses. ${ }^{3}$ Candida proliferation, especially with heavy growth, within the gut may result in diarrhoea and abdominal discomfort. ${ }^{4,5}$

Patients with diabetes mellitus (DM) are also susceptible to intestinal candidiasis, ${ }^{6,7}$ due to the effects of the hyperglycaemic state on the immune system such as dysfunction in the microbicidal activity, chemotaxis and the phagocytosis ability of the neutrophils. ${ }^{8}$ Additionally, there is increased death of leukocytes and decreased response to moderators of inflammation such as histamine and bradykinin among DM patients, ${ }^{9}$ resulting in a reduction in the capability of their immune systems to combat gastrointestinal infections.

Any of the Candida species can cause gastrointestinal candidiasis among diabetic patients; however, Candida albicans is the most common. ${ }^{10}$ Studies reporting prevalence of gastrointestinal candidiasis at the global and continental levels are scarce, and studies in various countries have yielded varying results. In Poland, Kowalewska et al. ${ }^{2}$ reported a prevalence of gastrointestinal candidiasis to be $75.47 \%$ among type $1 \mathrm{DM}$ patients; however, in India, the prevalence varied from $2.45 \%$ in North India to $9.7 \%$ in Goa. ${ }^{10}$ A study in Turkey reported prevalence of gastrointestinal candidiasis to be between $25 \%$ and $40 \%{ }^{11}$ A review of studies conducted across 
the African continent reported a non-uniform prevalence of gastrointestinal candidiasis with a continental prevalence of $12.42 \%$ but with a slightly higher prevalence in sub-Saharan Africa at $12.8 \%{ }^{9}$

The range of antifungal drugs available for treatment of gastrointestinal candidiasis is limited, with azoles, polyenes, allylamines, echinocandins and flucytosine as the available options. ${ }^{3}$ Both $C$. albicans and non-albicans Candida species such as Candida tropicalis, Candida glabrata and Candida krusei have shown high rates of intrinsic and acquired forms of antifungal resistance.5,12,13,14 There are suggested factors that predispose diabetic patients to gastrointestinal candidiasis and these factors include superimposed immunosuppression, use of steroids, use of antibiotics and poor glycaemic control. ${ }^{15}$

Despite the increase in the number of patients with DM, a non-communicable disease with the potential to induce conditions that increase the risk of mycosis, ${ }^{3,7}$ gastrointestinal candidiasis among diabetic patients remains an understudied condition, ${ }^{2,5}$ with few guidelines on the identification and treatment of such infections. ${ }^{16,17}$ In Uganda the problem is compounded by a lack of adequate microbiology facilities in most health laboratories, which inhibits the timely diagnosis and treatment of such infections. We aimed to determine antifungal susceptibility of gastrointestinal Candida isolates from DM patients with persistent diarrhoea at St. Francis Hospital Nsambya.

\section{Methods}

\section{Ethical considerations}

This study was approved by the Institutional Ethics Committee and Institutional Review Board of International Health Sciences University: approval number IHSUREC/0046. All participants provided written informed consent before the enrolment, and for participants younger than age 18 years, written informed consent was provided by a parent or legal guardian.

\section{Study design}

This was a cross-sectional study carried out at the Diabetes Clinic of St. Francis Hospital Nsambya, Kampala, Uganda. Two hundred and eighty DM patients attending the hospital's diabetes treatment clinic were assessed by a medical officer for clinical presentation consistent with diarrhoea.

\section{Inclusion criteria}

Patients with diabetes who had signs and symptoms of gastrointestinal infection such as diarrhoea, abdominal pain, bloating and heartburn were consented and enrolled in the study.

\section{Exclusion criteria}

Diabetic patients who had other immunosuppressive diseases, chronic diseases and those admitted in wards were not included in the study. Participants were randomly selected and informed consent was obtained as previously described. ${ }^{18,19}$ Briefly, a list of all the patients attending treatment at the clinic was obtained. Microsoft Excel (Microsoft Corporation, Redmond, Washington, United States) was used to generate numbers ranging between 1 and 500 to three digits. The numbers were typed on cards and the cards were placed in a box. Eligible patients who picked cards with numbers that were multiples of three were enrolled in the study. The cards were reshuffled each time a card was picked and picked cards were not replaced. Where repeated numbers were generated, only one card with such numbers was left in the box.

\section{Data and sample collection}

Clinical data were obtained from the consenting participants' medical records for demographic characteristics such as age, sex, type of diabetes and date of diabetes diagnosis plus information on use of antibiotics, corticosteroids, antidiabetes and antifungal medication. Stool specimens and blood samples were collected from the recruited participants according to the United States Centers for Disease Control and Prevention 2014 guidelines. ${ }^{16}$ In brief, a sterile, widemouthed spoon fitted with a graduated stool container was labelled for each participant and participants were instructed to produce about $10 \mathrm{~mL}$ of stool. The specimens were immediately delivered to the laboratory for subsequent analysis. One 4-mL fasting blood specimen was collected from each participant into fluoride/oxalate tubes and the plasma separated from the cells within $30 \mathrm{~min}$ after collection.

\section{Sample analyses}

Potassium hydroxide wet mounts and smears for Gram staining were prepared from each stool specimen to examine them for Candida blastoconidia and pseudohyphae. Specimens were cultured on Saboraud dextrose agar (Laboratorios Conda, Madrid, Spain) for colony counts and Candida differential agar (Himedia Laboratories, Mumbai, India) for species identification; cultures were incubated at $37{ }^{\circ} \mathrm{C}$ for $24-72 \mathrm{~h}$ and checked for growth. ${ }^{16}$ The Germ tube test and growth test at $45^{\circ} \mathrm{C}$ were performed to distinguish between C. albicans and C. dublinensis. Colonies on Sabouraud dextrose agar were enumerated and counts above $10^{5} \mathrm{CFU} /$ $\mathrm{mL}$ were interpreted as overgrowth indicative of infection, based on reviewed literature. ${ }^{2,16}$.

Following species identification of isolates, susceptibility testing was performed using the Kirby-Bauer disk diffusion test on a Mueller Hinton agar supplemented with $2 \%$ glucose and methylene blue (Himedia Laboratories, Mumbai, India). Inoculum was prepared by picking five distinct colonies of approximately $1 \mathrm{~mm}$ from 24-h-old culture grown on Sabouraud dextrose agar. Colonies were suspended in $5 \mathrm{~mL}$ of sterile $0.85 \%$ saline and turbidity adjusted to $0.5 \mathrm{McF}$ arland standard which corresponds to an approximate yeast density of $1 \times 10^{6}$ to $5 \times 10^{6}$ cells $/ \mathrm{mL}$. The surface of the Muller Hilton agar was dried and seeded 
with the yeast suspension using a sterile cotton swab by streaking the entire agar surface of the plate with the swab three times, turning the plate 60 degrees between each streaking. The inoculum was allowed to dry for 5 min -15 min with the lid in place, the antifungal discs were placed on the agar surface aseptically and then the plates were incubated at $35^{\circ} \mathrm{C} \pm 2{ }^{\circ} \mathrm{C}$ within 15 min after the discs were applied. The plates were examined for susceptibility after 20-24 h of incubation or at $48 \mathrm{~h}$ when insufficient growth was observed after $24 \mathrm{~h}$ incubation. Inhibitory zone diameters were measured in millimetres at the transitional point where growth abruptly decreased, as determined by a marked reduction in colony sizes. ${ }^{20}$

Antifungal susceptibility disks were used to test for susceptibility to two triazoles (fluconazole and itraconazole), two imidazoles (clotrimazole and miconazole) and one polyene (nystatin) (Laboratorios Conda, Madrid, Spain). Fasting blood glucose levels were tested using a point-of-care Accu-chek glucose meter (Roche Diabetes Care, Inc., Ängelholm, Sweden) and glycated hemoglobin levels were determined using an automated glycated hemoglobin 501 analyser (HemoCue AB, Ängelholm, Sweden).

\section{Quality control}

Growth testing for all culture media was performed using reference Candida strains (Candida albicans ATCC 10231, Candida glabrata ATCC 15126, Candida krusei ATCC 24408, Candida tropicalis ATCC 750) and negative control strains (Escherichia coli ATCC 25922 and Staphylococcus aureus ATCC 25923) as recommended by the manufacturers. Susceptibility testing was performed in adherence to National Committee for Clinical Laboratory Standards guidelines. ${ }^{20}$ Procedures for Gram staining, serial dilutions and culture techniques were performed according to protocols developed by the American Society for Microbiology. ${ }^{21}$ Blood glucose and glycated hemoglobin determination were performed on calibrated devices following the manufacturer's manual.

\section{Statistical analysis}

Data were entered in an Excel spreadsheet and analysed using STATA special edition, Version 10.0 (StataCorp, College Station, Texas, United States). Data regarding study population characteristics, proportion of patients with gastrointestinal candidiasis, species distribution and susceptibility profiles were analysed using frequency distributions and 95\% confidence intervals. Bivariate analysis through the use of chi-square tables, and multivariate logistic regression were used to analyse associations between risk factors and gastrointestinal candidiasis. Statistical significance was assumed to exist if $p$-values were less than 0.05 . The risk factors studied were age of the participants, sex, glycaemic control ('good' control = glycated haemoglobin level $<7.0 \%$; 'poor' control = glycated haemoglobin $>7.0 \%$ ), history of antibiotic therapy, history of corticosteroid therapy and type of DM. Participants were analysed in four age groups: children
(< 18 years), youth (18-40 years), adult (41-65 years) and elderly ( $>65$ years). Diabetes type was classified based on diagnostic information on the patient's form into type 1 and type 2 DM. The history of therapies was classified as Yes if the patient had treatment for more than 2 weeks but less than 1 month earlier or No if the patient had therapies either for less than 2 weeks or more than 1 month earlier.

\section{Results}

Two hundred and forty-one study participants were recruited into the study (Table 1). One hundred and seventeen (48.5) of the participants were female patients; $82(34.02 \%)$ patients had type $1 \mathrm{DM}$ and the rest had type 2 DM. The mean age of the participants was 43 years (95\% confidence interval: 41-46); among type $1 \mathrm{DM}$ patients the mean age was 21 years (95\% confidence interval: $19-22$ years) and in type $2 \mathrm{DM}$ patients this was 55 years (95\% CI: 53-57 years). The average fasting blood glucose levels in the study participants was $9.9 \mathrm{mmol} / \mathrm{L}$ (standard deviation $=2.3 \mathrm{mmol} / \mathrm{L}$ ), and average glycated haemoglobin level was $9.3 \%$ (standard deviation $=1.6 \%$ ).

\section{Proportion of diabetes mellitus patients with gastrointestinal candidiasis}

Cultures from $37(15.4 \%)$ patients had colony counts consistent with gastrointestinal candidiasis $\left(\geq 1 \times 10^{5}\right.$ colonyforming units $/ \mathrm{mL}$ of stool). Among infected patients, 11 (29.7\%) had type $1 \mathrm{DM}$, and $26(70.3 \%)$ had type $2 \mathrm{DM}$ $(p=0.706)$. About one-third of patients with gastrointestinal

TABLE 1: Characteristics of the study participants at enrolment $(N=241)$, Kampala, Uganda, March 2017 to December 2017.

\begin{tabular}{lcc}
\hline Variable & \multicolumn{2}{c}{ Observation } \\
\cline { 2 - 3 } & $\boldsymbol{n}$ & $\%$ \\
\hline Male patients, frequency (\%) & 124 & 51.4 \\
Female patients, frequency (\%) & 117 & 48.6 \\
Age (years), mean (95\% confidence interval) & 43 & 41,46 \\
Type 1 diabetes mellitus, frequency (\%) & 82 & 34.0 \\
Type 2 diabetes mellitus, frequency (\%) & 159 & 66.0 \\
Blood glucose (mmol/L), mean (standard deviation) & 9.9 & 2.3 \\
HbA1c (\%), mean (standard deviation) & 9.3 & 1.6 \\
\hline
\end{tabular}

HbA1c, glycated hemoglobin.

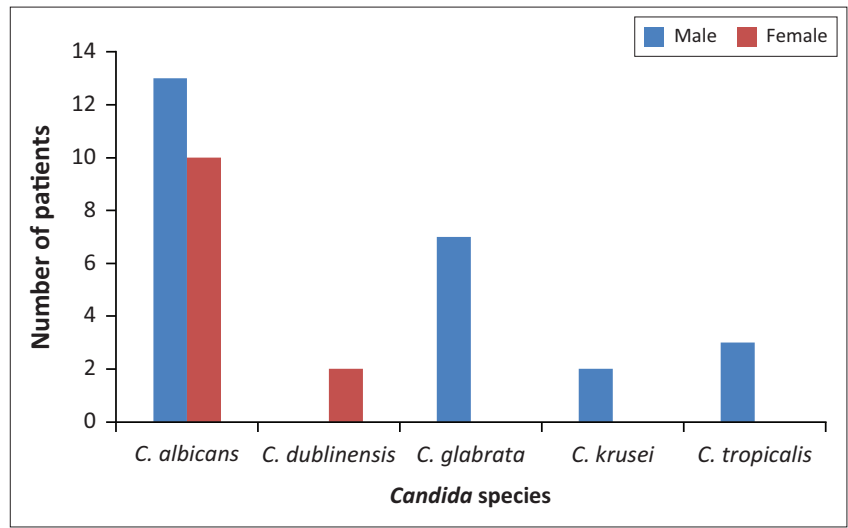

FIGURE 1: Distribution of Candida species by sex $(n=37)$, Kampala, Uganda, March 2017 to December 2017. 
TABLE 2: Antifungal susceptibility profile of Candida isolates from diabetes mellitus patients ( $n=37$ isolates), Kampala, Uganda, March 2017 to December 2017.

\begin{tabular}{|c|c|c|c|c|c|c|c|}
\hline \multirow[t]{2}{*}{ Isolate } & \multicolumn{2}{|c|}{ Resistant (\%) } & \multicolumn{2}{|c|}{ Intermediate (\%) } & \multicolumn{2}{|c|}{ Sensitive (\%) } & \multirow[t]{2}{*}{ Total } \\
\hline & $n$ & $\%$ & $n$ & $\%$ & $n$ & $\%$ & \\
\hline \multicolumn{8}{|l|}{ Fluconazole } \\
\hline C. albicans & 0 & 0.0 & 3 & 13.0 & 20 & 87.0 & 23 \\
\hline C. dubliniensis & 1 & 50.0 & 1 & 50.0 & 0 & 0.0 & 2 \\
\hline C. glabrata & 0 & - & 4 & 57.1 & 3 & 42.9 & 7 \\
\hline C. krusei & 2 & 100.0 & 0 & - & 0 & - & 2 \\
\hline C. tropicalis & 0 & - & 1 & 33.3 & 2 & 66.7 & 3 \\
\hline \multicolumn{8}{|l|}{ Itraconazole } \\
\hline C. albicans & 0 & - & 0 & - & 23 & 100.0 & 23 \\
\hline C. dubliniensis & 0 & - & 0 & - & 2 & 100.0 & 2 \\
\hline C. glabrata & 0 & - & 2 & 28.6 & 5 & 71.4 & 7 \\
\hline C. krusei & 0 & - & 2 & 100.0 & 0 & - & 2 \\
\hline C. tropicalis & 0 & - & 0 & - & 3 & 100.0 & 3 \\
\hline \multicolumn{8}{|l|}{ Clotrimazole } \\
\hline C. albicans & 2 & 8.7 & 9 & 39.1 & 12 & 52.2 & 23 \\
\hline C. dubliniensis & 1 & 50.0 & 0 & - & 1 & 50.0 & 2 \\
\hline C. glabrata & 3 & 42.9 & 3 & 42.9 & 1 & 14.3 & 7 \\
\hline C. krusei & 1 & 50.0 & 1 & 50.0 & 0 & - & 2 \\
\hline C. tropicalis & 0 & - & 2 & 66.7 & 1 & 33.3 & 3 \\
\hline \multicolumn{8}{|l|}{ Miconazole } \\
\hline C. albicans & 6 & 26.1 & 9 & 39.1 & 8 & 34.8 & 23 \\
\hline C. dubliniensis & 2 & 100.0 & 0 & - & 0 & - & 2 \\
\hline C. glabrata & 7 & 100.0 & 0 & - & 0 & - & 7 \\
\hline C. krusei & 2 & 100.0 & 0 & - & 0 & - & 2 \\
\hline C. tropicalis & 1 & 33.3 & 2 & 66.7 & 0 & - & 3 \\
\hline \multicolumn{8}{|l|}{ Nystatin } \\
\hline C. albicans & 0 & - & 0 & - & 23 & 100 & 23 \\
\hline C. dubliniensis & 0 & - & 0 & - & 2 & 100 & 2 \\
\hline C. glabrata & 0 & - & 0 & - & 7 & 100 & 7 \\
\hline C. krusei & 0 & - & 0 & - & 2 & 100 & 2 \\
\hline C. tropicalis & 0 & - & 0 & - & 3 & 100 & 3 \\
\hline
\end{tabular}

candidiasis $(25,67.6 \%)$ were female, and $12(32.4 \%)$ were male $(p=0.009)$.

The majority of the isolates were C. albicans $(n=23,62.2 \%)$, followed by C. glabrata $(n=7,18.9 \%), C$. tropicalis $(n=3,8.1 \%)$, Candida dublinensis $(n=2,5.4 \%)$ and C. krusei $(n=2,5.4 \%)$. Among female patients, only C. albicans and C. dubliniensis were isolated (Figure 1). C. glabrata, C. krusei and C. tropicalis were isolated exclusively from male patients.

\section{Antifungal susceptibility of gastrointestinal Candida isolates}

A total of 25 of the 37 isolates $(67.6 \%)$ were susceptible to fluconazole and $3 / 37(8.1 \%)$ isolates were resistant to fluconazole. Itraconazole susceptibility was observed in $33(89.2 \%)$ isolates; $15(40.5 \%)$ isolates were susceptible to clotrimazole, while $7(18.9 \%)$ were resistant and 18 $(48.6 \%)$ isolates were resistant to miconazole, while $8(21.6 \%)$ were sensitive. All isolates were susceptible to nystatin (Table 2).

\section{Patient factors associated with gastrointestinal candidiasis}

There were $12(34.4 \%)$ male, culture-positive patients and 25 $(67.6 \%)$ female, culture-positive patients $(p=0.01)$. Twentyfive $(67.6 \%)$ of the culture-positive patients reported prior use of antifungal drugs, whereas the rest had no history of antifungal drug use in the past weeks $(p<0.001) ; 26(70.3 \%)$ culture-positive patients had used antibiotics and $11(29.7 \%)$ had not used antibiotics in the past weeks; 14 (37.8\%) culturepositive patients had used corticosteroids and the rest had not used corticosteroids in the past weeks $(p<0.001)$ (Table 3). Thirty-five had poor glucose control, and 20 were hyperglycaemic. Based on glycated haemoglobin results,

TABLE 3: Relationship between patient factors and gastrointestinal candidiasis ( $n=37$ ), Kampala, Uganda, March 2017 to December 2017.

\begin{tabular}{|c|c|c|c|c|c|c|c|}
\hline \multirow[t]{3}{*}{ Variable } & \multirow[t]{3}{*}{ Observation } & \multicolumn{5}{|c|}{ Culture result } & \multirow[t]{3}{*}{$p$} \\
\hline & & \multicolumn{2}{|c|}{ Growth } & \multicolumn{2}{|c|}{ No significant growth } & \multirow[t]{2}{*}{ Total } & \\
\hline & & $n$ & $(\%)$ & $n$ & $(\%)$ & & \\
\hline \multirow[t]{4}{*}{ Age group $\dagger$} & Children (< 18 years) & 5 & 17.2 & 24 & 83.8 & 29 & 0.26 \\
\hline & Youth (18-40 years) & 7 & 11.9 & 52 & 88.1 & 59 & - \\
\hline & Adults (41-65 years) & 12 & 12.4 & 85 & 87.6 & 97 & - \\
\hline & Elderly (> 65 years) & 13 & 23.2 & 43 & 76.8 & 56 & - \\
\hline \multirow[t]{2}{*}{ Sex } & Male & 12 & 9.6 & 112 & 90.3 & 124 & 0.01 \\
\hline & Female & 25 & 21.4 & 92 & 78.6 & 117 & - \\
\hline \multirow[t]{2}{*}{ Type of diabetes mellitus } & Type 1 & 11 & 13.4 & 71 & 86.6 & 82 & 0.71 \\
\hline & Type 2 & 26 & 12.7 & 133 & 83.6 & 159 & - \\
\hline \multirow[t]{2}{*}{ Fasting blood glucose } & Normal & 17 & 16.4 & 117 & 87.3 & 134 & 0.66 \\
\hline & Hyperglycaemic (> $6.1 \mathrm{mmol} / \mathrm{L}$ ) & 20 & 18.7 & 87 & 81.3 & 107 & - \\
\hline \multirow[t]{2}{*}{ Glycaemic control } & Good $(<7.0 \%)$ & 2 & 1.2 & 159 & 98.7 & 161 & $\leq 0.001$ \\
\hline & Poor & 35 & 43.7 & 45 & 56.3 & 80 & - \\
\hline \multirow[t]{2}{*}{ Antibiotic use $\dagger$} & Yes & 26 & 63.4 & 15 & 36.6 & 41 & $\leq 0.001$ \\
\hline & None & 11 & 5.5 & 189 & 94.5 & 200 & - \\
\hline \multirow[t]{2}{*}{ Antifungal use $\dagger$} & Yes & 25 & 71.4 & 10 & 28.6 & 35 & $\leq 0.001$ \\
\hline & None & 12 & 5.8 & 194 & 94.2 & 206 & - \\
\hline \multirow[t]{2}{*}{ Corticosteroid use $\dagger$} & Yes & 14 & 77.8 & 4 & 22.2 & 18 & $\leq 0.001$ \\
\hline & None & 23 & 10.3 & 200 & 89.7 & 223 & - \\
\hline
\end{tabular}

$\dagger$, Use of antibiotics, antifungals or corticosteroids was defined as treatment for more than 2 weeks less than 1 month ago. 
$2(5.4 \%)$ culture-positive patients had good glycaemic control and the remaining $35(94.6 \%)$ culture-positive patients had poor glycaemic control $(p<0.001)$.

\section{Discussion}

The overall prevalence of intestinal candidiasis in this study was $15.4 \%$ (37 isolates found among 241 patients). This is considerably lower than other findings such as $21.5 \%$ in Cameroon, ${ }^{22} 75.47 \%$ in Poland in $2015^{2}$ and $41.1 \%$ in Mexico. ${ }^{23}$ The prevalence in this study was also lower than the overall prevalence in sub-Saharan Africa, which was estimated to be $23.4 \%{ }^{8}$ Gurleen and Savio ${ }^{24}$ in India, however, reported a lower prevalence $(9.7 \%)$. Previous authors have noted a wide variation in the prevalence of candidiasis depending on region, population surveyed and even the research methods used. ${ }^{3}$ Whereas most studies used similar culture-based methods, the quantification threshold for colony-forming units of the culture colonies have varied. In this study, a threshold range of $10^{5} \mathrm{CFU}$ was considered significant for growth, whereas in the study in Poland, ${ }^{2}$ a wider range $\left(10^{3} \mathrm{CFU}-10^{6} \mathrm{CFU}\right)$ was considered. This would have accounted for the significantly higher prevalence in their study.

In the current study, female patients had a higher prevalence rate compared to male patients $(21.4 \%$ vs $9.7 \% ; p=0.009)$. A study conducted in Vienna, Austria, on burn patients found a female predisposition in systemic and related candidiasis. ${ }^{25}$ The predilection of gastrointestinal candidiasis in female patients is poorly understood and there is no proper explanation for the predisposition. ${ }^{26}$

\section{Species distribution of Candida isolates}

C. albicans accounted for the majority of isolates in the current study. This is consistent with other studies that identified it as the most common isolate from clinical materials,,$^{27,28}$ and could be attributed to the fact that C. albicans is highly adapted to the human mucosal surfaces and possesses virulence factors such as protease production and biofilm formation. ${ }^{3,29}$ These enhance its chances of survival in the gastrointestinal tract. Omrani et al. ${ }^{9}$ in their review of African studies also found a predominance of C. albicans. Non-albicans species in general accounted for a larger number of isolates in studies by Banerjee et al. ${ }^{30}$ in India, as well as in Brazil and Chile. ${ }^{31}$ No mixed species infections were encountered in this study, unlike the studies in Poland ${ }^{2}$ and India. ${ }^{30}$ Among non-albicans species in this study C. glabrata was predominant, accounting for half $(7 / 14)$ of all non-albicans isolates. This was followed by C. tropicalis $(3 / 14)$, C. krusei $(2 / 14)$ and C. dubliniensis $(2 / 14)$. Species diversity was greater in male patients and type 2 DM patients; however, the latter could simply be a reflection of the fact that the type 2 DM sub-group accounted for the majority of patients. The relationship could perhaps be better established with a cohort study design.

\section{Antifungal susceptibility patterns of Candida isolates}

There are relatively fewer options for the treatment of mycoses compared with antibiotics. Fluconazole is a narrow spectrum fungistatic azole with good activity against yeasts; however, from the mid-1990s concerns about resistance have persisted. ${ }^{3}$ This study found that $87 \%$ of $C$. albicans isolates were fluconazole-susceptible. Similarly, the study in Poland ${ }^{2}$ and a study conducted in 2013 in India ${ }^{32}$ also reported fluconazole susceptibility in over $80 \%$ of C. albicans isolates. Fluconazole resistance among non-albicans species was found to be $21 \%$. This was considerably lower than observations from the Polish study ${ }^{2}$ where $56 \%$ of nonalbicans species were susceptible to fluconazole. This has implications for clinical therapy since the guidelines for the treatment of non-albicans infection in Uganda require fluconazole.

Intrinsic resistance in non-albicans species has been documented in species such as C. krusei, and reduced susceptibility in C. glabrata and C. guilliermondii has been reported. ${ }^{33,34}$ Candida tropicalis has been known to exhibit fluconazole resistance up to $31.3 \%^{28}$; however, this could be due to the use of a panel that mostly comprised high-potency drugs normally reserved for systemic infections, such as amphotericin B and voriconazole. In this study C. krusei, was also the most fluconazole-resistant strain. This strain has been known to exhibit intrinsic fluconazole resistance; Sanguinetti et al. ${ }^{28}$ reported an estimated global fluconazole resistance of $78 \%$ in C. krusei.

Itraconazole has a wider spectrum of activity than fluconazole, and is normally effective against both fluconazole-susceptible and fluconazole-resistant Candida strains. ${ }^{17}$ Lesser susceptibility, however, was observed in 2 C. glabrata and both C. krusei isolates. The Polish study, however, found that only $28 \%$ of C. albicans and $11 \%$ of nonalbicans species were itraconazole susceptible. Higher rates of resistance were observed in the imidazoles; $18.9 \%$ of isolates were resistant to clotrimazole and nearly half were resistant to miconazole.

It is worth noting that a number of patients in this study had prior exposure to antifungal medications, especially azoles, which were mostly used to treat dermatomycoses and Candida. Clotrimazole and miconazole are commonly used over-the-counter antifungals, and these could therefore be a driver for the reduced susceptibility and resistance patterns observed in some patient isolates.

All isolates in this study were susceptible to nystatin, which is consistent with reports that document low rates of polyeneclass antifungal resistance. ${ }^{3,17,33}$ Nystatin carries the additional advantage of being a low-cost medicine and is widely available in many formulations including tablets, suspension and topical preparations. In Uganda, the treatment plan for oropharyngeal candidiasis and gastrointestinal candidiasis 
may require the use of nystatin preparations, which replaces the expensive and less available medicines such as caspofungins.

\section{Patient factors associated with gastrointestinal candidiasis}

There was no significant association between the diabetes type and gastrointestinal candidiasis. Gosiewski et al. ${ }^{34}$ also found no association, despite a higher prevalence among those with type $2 \mathrm{DM}$ patients. This was contrary to Kumar et al., ${ }^{35}$ who found a higher prevalence among type $1 \mathrm{DM}$.

Gastrointestinal candidiasis was more common among female patients than among male patients $(p=0.01)$ and among patients with poor glycaemic control $(p \leq 0.001)$ than among those with good glycaemic control. The use of antifungals ( $p \leq$ $0.001)$, antibiotics $(p \leq 0.001)$ and corticosteroids $(p \leq 0.001)$ was a predisposing factor to gastrointestinal candidiasis. Similar findings were reported by Banerjee et al., ${ }^{30}$ in India, where a majority of patients were on antibiotic and corticosteroid therapy. Antibiotics, especially the broad-spectrum variety, are known to interfere with the balance of gut microbiota in the human body. $27,36,37$ In doing so, they create a favourable environment for the proliferation of yeasts, and some studies have reported a possible influence on drug resistance profiles. Ben-Ami et al., ${ }^{37}$ found a significant association between the use of antibiotics such as carbapenems, clindamycin and colistin and fluconazole resistance, but in this study the class of antibiotics used by diabetic patients was not reported. Use of antifungal therapy could also select for more resistant strains. This was demonstrated by Lortholary et al., ${ }^{38}$ using data from a prospective surveillance programme; the authors observed high rates of isolation of fluconazole-resistant Candida species following the recent use of the drug. In this study, poor antifungal susceptibility at baseline level and inappropriate doses of antifungal drugs could be responsible for the association that was observed.

Increased age is usually associated with decreased effectiveness of the immune response. ${ }^{1,17}$ The elderly patients and adults accounted for the majority of infections, but there was no significant association between age and gastrointestinal candidiasis. Therefore, this observation could simply be a reflection of the study population, most of which comprised adults and elderly patients. In contrast, Banerjee et al. ${ }^{30}$ observed a higher isolation rate in children (0-12 years), and attributed it to the weaker immune systems in such populations. Given the adult: paediatric ratio in that study (1:1.9), however, the sampling method may have also had an influence on this result.

Corticosteroid use was also associated with gastrointestinal candidiasis. This has also been observed by Glavey et al., ${ }^{39}$ in their cross-sectional study, and Madhumati and Rajendran. ${ }^{40}$ Kakeya et al. ${ }^{41}$ and Fardet et al. ${ }^{42}$ reported an increased risk of susceptibility to opportunistic infections in patients exposed to corticosteroids.

Most patients with gastrointestinal candidiasis in this study had poor glucose control. Studies investigating the association between the two have yielded varying results. Findings from this study are similar to the report by OlczakKowalczyk et al., ${ }^{43}$ but contrary to studies conducted by Suarez et al., ${ }^{44}$ Kowalewska et al. ${ }^{2}$ and Arslan et al. ${ }^{29}$ which did not find association between poor glycaemic control and candidiasis.

\section{Recommendations}

As a package for the diagnosis and management of gastrointestinal candidiasis, speciation of Candida isolates should be performed, and antifungal susceptibility profiles established to guide patient therapy. The speciation is important, since species within the Candida genus differ widely, both in their ability to cause infection and also in their susceptibility to antifungal agents. Nystatin was shown to have excellent antifungal activity in this study and could be considered for empirical therapy in settings where inadequate resources may inhibit antifungal susceptibility testing.

\section{Limitations}

This study enrolled only participants who complained of gastrointestinal symptoms and several asymptomatic patients could have been left out. This might have reduced the prevalence of gastrointestinal candidiasis. Routine culture and sensitivity testing was conducted and very sensitive techniques such as molecular techniques were not performed. This could have reduced the detection of Candida organisms.

\section{Conclusion}

Prevalence of gastrointestinal candidiasis was relatively low among the participants of this study. The infection is associated with female sex, poor glycaemic control and previous use of antifungals, antibiotics and corticosteroids. Nystatin can be a drug of choice in the treatment of gastrointestinal candidiasis, if the suspension or tablet formulations can be made available.

\section{Acknowledgements}

The authors are highly grateful to the diabetic patients who accepted to participate in the study. The author wishes to sincerely acknowledge the contributions of the administration and staff of St. Francis Hospital Nsambya Diabetes Centre, the staff of the International Health Sciences University Laboratory and teaching staff, especially Mr Taremwa Ivan Mugisha.

\section{Competing interests}

The authors have declared that no competing interest exists.

\section{Authors' contributions}

C.O. and A.P.O. conceived the topic and collected the data, C.O. analysed the data, B.M. and E.O. drafted the manuscript, 
and J.C.O., V.A. and C.A. edited the manuscript. All authors read and approved the contents of the manuscript.

\section{Sources of support}

This research received no specific grant from any funding agency in the public, commercial or not-for-profit sectors.

\section{Data availability statement}

Data sharing is not applicable to this article as no new data were created or analysed in this study.

\section{Disclaimer}

The views and opinions expressed in this article are those of the authors and do not necessarily reflect the official policy of any affiliated agency of the authors.

\section{References}

1. Mahon RC, Lehman CD, Manuselis G. Textbook of diagnostic microbiology. 5th ed. St Louis. MO: Saunders Elsevier; 2015.

2. Kowalewska B, Kawko $M$, Zorena $K$, Myśliwiec $M$. Yeast-like fungi in the gastrointestinal tract in children and adolescents with Diabetes type 1 . Pediat Endocrinol Diabetes Metab. 2014;20(4):170-177. https://doi.org/10.18544/ PEDM-20.04.0017

3. Anaissie EJ, McGinnis RM, Pfaller AM. Clinical mycology. 2nd ed. St Louis, MO: Elsevier; 2009.

4. Lamps WL. Surgical pathology of the gastrointestinal system: Bacterial, fungal, viral and parasitic infections. 1st ed. New York, NY: Springer; 2009.

5. Wang ZK, Yang YS, Stefka AT, Sun G, Peng LH. Review article: Fungal microbiota and digestive diseases. Aliment Pharmacol Ther. 2014;39(8):751-766. https://doi. org/10.1111/apt.12665

6. Lamichhane RS, Boaz K, Natarajan S, Shrestha M. Assessment of Candidal carriage in patients with type II diabetes mellitus. J Path Nep. 2015;5(9):733-738. https:// doi.org/10.3126/jpn.v5i9.13784

7. Mandal SM, Mahata D, Migliolo L, et al. Glucose directly promotes antifungal resistance in the fungal pathogen, Candida spp. J Biol Chem. 2014;289(37): 25468-25473. https://doi.org/10.1074/jbc.C114.571778

8. Jafar $\mathrm{N}$, Edriss $\mathrm{H}$, Nugent $\mathrm{K}$. The effect of short-term hyperglycemia on the innate immune system. Am J Med Sci. 2016;351(2):201-211. https://doi.org/10.1016/j. amjms.2015.11.011

9. Omrani SA, Pecen L, Rajek P, Raghubir N, Zigmond J. Prevalence of invasive and superficial Candida infections in Africa and Middle East; a systematic review and meta-analysis. 114th Meeting of the American Society for Microbiology (ASM), Boston, MA, May; 2014; pp. 17-20, Poster number 1273.

10. Soyucen E, Gulcan A, Aktuglu-Zeybek AC, Onal H, Kiykim E, Aydin A. Differences in the gut microbiota of healthy children and those with type 1 diabetes. Pediatr Int. 2014;56(3):336-343. https://doi.org/10.1111/ped.12243

11. Alba-Loureiro CT, Munhoz DC, Martins OJ, Cerhiaro AGC, Scavone RC, Sannomiya P. Neutrophil function and metabolism in individuals with diabetes mellitus. Braz J Med Biol Res. 2007;40(8):1037-1044. https://doi.org/10.1590/S0100-879X 2006005000143

12. Deorukhkar C S, Saini S, Mathew S. Non-albicans Candida Infection: An Emerging Threat. Interdiscip Perspect Infect Dis. 2014;2014:615958. https://doi.org/10.1155/ 2014/615958

13. Maubon D, Garnaud C, Calandra T, Sanglard D, Cornet M. Resistance of Candida spp. to antifungal drugs in the ICU: Where are we now? J Intensive Care Med. 2014;40(9):1241-1255. https://doi.org/10.1007/s00134-014-3404-7

14. Doi AM, Pignatari ACC, Edmond MB, et al. Epidemiology and microbiologic characterization of nosocomial candidemia from a Brazilian national surveillance program. PLoS One. 2016;11(1):e0146909. https://doi.org/10.1371/journal. pone.0146909

15. Geerlings SE, Hoepelman. Immune dysfunctuion in patients with diabetes mellitus (DM). FEMS Immunol Med Micobiol. 1999;26;(3-4):259-265. https://doi. org/10.1111/j.1574-695X.1999.tb01397.x

16. Centres for Disease Control and Prevention. Stool specimens - Specimen collection. DPDx - Laboratory Identification of Parasitic Diseases of Public Health Concern [homepage on the Internet]. 2016 [cited 2017 Feb 04]. Available from: https://www.cdc.gov/dpdx/diagnosticprocedures/stool/specimencoll.html

17. Kauffman AC, Pappas GP, Sobel JD, Dismukes WE. Essentials of clinical mycology. 2nd ed. New York, NY: Springer.
18. Jeehyoung K, Wonshik S. How to do random allocation (randomization). Clin Orthop Surg. 2014;6(1):103-109. https://doi.org/10.4055/cios.2014.6.1.103

19. Dettori J. The random allocation process: Two things you need to know. Evid Based Spine Care J. 2010;1(3):7-9. https://doi.org/10.1055/s-0030-1267062

20. National Committee for Clinical Laboratory Standards. Method for antifungal disk diffusion susceptibility testing of yeasts; approved guideline. Wayne, PA: NCCLS 2009.

21. American Society for Microbiology. Laboratory protocols [homepage on the Internet]. American Society for Microbiology; 2016 [cited 2017 Feb 04]. Available from: http://www.asmscience.org/content/education/protocol/

22. Bissong $M$, Azodo CC, Agbor MA, Nkuo-akenji T, Fon P. Oral health status of diabetes mellitus patients in Southwest Cameroon. Odontostomatol Trop. 2015;38(150):49-57

23. Martinez RFF, Jaimes-Aveldañez A, Hernández-Pérez F, Arenas R, Miguel GFS, Oral Candida spp carriers: Its prevalence in patients with type 2 diabetes Oral Candida spp carriers: Its prevalence in patients with type 2 diabetes
mellitus. An Bras Dermatol. 2013;88(2):222-225. https://doi.org/10.1590/S0365mellitus. An Bras Derm

44. Gurleen K, Savio R. Prevalence of Candida in Diarrhoeal Stools. J Dent Medi Sci. 2016;15(4):47-49.

25. Rubaihayo J, Tumwessigye NM, Konde-Lule J, Wamani H, Nakku-Joloba E, Makumbi F. Frequency and distribution patterns of opportunistic infections associated with HIV/AIDS in Uganda. BMC Res Notes. 2016;9(1):501. https://doi. org/10.1186/s13104-016-2317-7

26. Loster JE, Wieczorek A, Loster BW. Correlation between age and Candida species infections of complete denture wearers: A retrospective analysis. Clin Interv Aging. 2016;2016(11):1707-1714. https://doi.org/10.2147/CIA.S116658

27. Flevari A, Theodorakopoulou M, Velegraki A, Armaganidis A, Dimopoulos G. Treatment of invasive candidiasis in the elderly: A review. Clin Interv Aging. 2013;2013:8:1199. https://doi.org/10.2147/CIA.S39120

28. Sanguinetti M, Posteraro B, Lass-Flörl C. Antifungal drug resistance among Candida species: Mechanisms and clinical impact. Mycoses. 2015;58(Suppl 2): 2-13. https://doi.org/10.1111/myc.12330

29. Arslan S, Koç AN, Sekerci AE, et al. Genotypes and virulence facttors of Candida species isolated from oral cavities of patients with type 2 diabetes mellitus. Turk J Med Sci. 2016;46(1):18-27. https://doi.org/10.3906/sag-1405-73

30. Banerjee $P$, Kaur R, Uppal B. Study of fungal isolates in patients with chronic diarrhea at a tertiary care hospital in North India. J Mycol Med. 2013;23(1):21-26. https://doi.org/10.1016/j.mycmed.2012.12.002

31. Sardi OCJ, Scorzoni L, Bernardi T, Fusco-Almeida MA, Mendes GSJM. Candida species: Current epidemiology, pathogenicity, biofilm formation, natura antifungal products and new therapeutic options. J Med Microbiol. 2013;62(1): 10-24. https://doi.org/10.1099/jmm.0.045054-0

32. Premkumar J, Ramani P, Chandrasekar T, Natesan A, Premkumar P. Detection of species diversity in oral candida colonization and anti-fungal susceptibility among non-oral habit adult diabetic patients. J Nat Sci Biol Med. 2014;5(1):148. https:// doi.org/10.4103/0976-9668.127315

33. Spampinato C, Leonardi D. Candida infections, causes, targets, and resistance mechanisms: Traditional and alternative antifungal agents. BioMed Res Int. 2013;2013:204237. https://doi.org/10.1155/2013/204237

34. Gosiewski T, Salamon D, Szopa M, Sroka A, Malecki MT, Bulanda M. Quantitative evaluation of fungi of the genus Candida in the feces of adult patients with type and 2 diabetes-a pilot study. Gut Pathog. 2014;6(1):1. https://doi.org/10.1186/ s13099-014-0043-z

35. Kumar BV, Padshetty NS, Bai KY, Rao MS. Prevalence of Candida in the oral cavity of diabetic subjects. J Assoc Physicians India. 2005;53:599-602.

36. Vaishnavi C, Kaur S, Prakash S. Speciation of fecal Candida isolates in antibioticassociated diarrhea in non-HIV patients. Jpn J Infect Dis. 2008;61(1):1-4.

37. Ben-Ami R, Olshtain-Pops K, Krieger M, et al. Antibiotic exposure as a risk factor for fluconazole-resistant Candida bloodstream infection. Antimicrob Agents Chemother. 2012;56(5):2518-2523. https://doi.org/10.1128/AAC.05947-11

38. Lortholary O, Desnos-Ollivier M, Sitbon K, Fontanet A, Bretagne S, Dromer F. Recent exposure to caspofungin or fluconazole influences the epidemiology of
candidemia: A prospective multicenter study involving 2,441 patients. Antimicrob Agents Chemother. 2011;55(2):532-538. https://doi.org/10.1128/AAC.01128-10

39. Glavey S V, Keane N, Power M, O'Regan AW. Posterior pharyngeal candidiasis in the absence of clinically overt oral involvement: A cross-sectional study. Lung. 2013;191(6):663-668. https://doi.org/10.1007/s00408-013-9503-3

40. Madhumati B, Rajendran R. Evaluation of chrom agar in speciation of Candida species from various clinical samples in a tertiary care hospital. Int J Curr Microbiol App Sci. 2015;4(9):463-472.

41. Kakeya H, Izumikawa K, Yamada K, et al. Concurrent subcutaneous Candida. 2014

42. Fardet L, Petersen I, Nazareth I. Common infections in patients prescribed systemic glucocorticoids in primary care: A population-based cohort study. PLoS Med. 2016;13(5):e1002024. https://doi.org/10.1371/journal.pmed.1002024

43. Olczak-Kowalczyk D, Pyrżak B, Dąbkowska M, et al. Candida spp. and gingivitis in children with nephrotic syndrome or type 1 diabetes. BMC Oral Health. 2015;15(1):57. https://doi.org/10.1186/s12903-015-0042-6

44. Suárez LB, Alvarez MI, De Bernal M, Collazos A. Candida species and other yeasts in the oral cavities of type 2 diabetic patients. Colombia Méd. 2013:44(1):26-30. https://doi.org/10.25100/cm.v44i1.1040 